\title{
Virus tropical en la clase de E/LE: cómo trabajar la narración visual, la identidad y el plurilingüismo con una novela gráfica
}

Agustín CORTI

Universidad de Salzburgo agustin.corti@sbg.ac.at

Resumen: El presente artículo es un aporte al desarrollo de la alfabetización visual en la clase de E/LE a partir de la novela gráfica Virus tropical de Powerpaola. Parte de un enfoque narratológico a fin de fomentar las competencias socioculturales y la conciencia de la identidad de los aprendientes respecto al español como una lengua pluricéntrica. La secuencia didáctica está estructurada en dos partes que se centran en el desarrollo integrado de las competencias propuestas.

Palabras clave: alfabetización visual, identidad, plurilingüismo, variedades del español.

Abstract: the paper presents an approach to the development of visual literacy in S/FL through the graphic novel Virus tropical from Powerpaola. Within a narratological approach it elaborates exercises on sociocultural competence and identity awareness of learners on behalf of Spanish as a pluricentric language. The didactic proposal is structured in two stages that integrate the proposed competences.

Keywords: visual literacy, identity, plurilinguism, varieties of Spanish. 


\section{Introducción}

La narración visual permite fomentar la alfabetización visual a partir de la unidad de dos códigos, uno gráfico y otro verbal. ${ }^{1}$ A través de ambos elementos, el medio construye una narración que abre diversas posibilidades para la enseñanza del Español como Lengua Segunda o Extranjera (E/LE). En la secuencia didáctica propuesta en el siguiente artículo parto de la narración autobiográfica Virus tropical de Powerpaola (Powerpaola, 2013) a fin de fomentar la alfabetización visual a través del desarrollo de las competencias socioculturales y de la conciencia identitaria respecto al aprendizaje de lenguas.

La competencia visual, que tiene que ver con procesos complejos de procesamiento de la información e interpretación (Arnheim, 1986; Mitchell, 1994: 7), debe aprenderse, aunque el sentido de la vista forme parte de las capacidades naturales de los seres humanos. Comprender visualmente algo implica interpretar los signos visuales y reflexionar sobre su función en las imágenes. La utilización de imágenes en el aula de $\mathrm{E} / \mathrm{LE}$ requiere, por lo tanto, que los docentes conozcan su proceso de producción y recepción, así como su carácter cultural (Kress \& Leeuwen, 2006; Rose, 2001), a fin de poder establecer las metas que se pretenden y es posible alcanzar con determinados textos visuales (Hecke \& Surkamp, 2010).

En la experiencia práctica propuesta aquí se hace uso de una novela gráfica, es decir, de un medio que une los códigos visual y verbal a fin de (re-)construir una identidad autobiográfica. En ella es fundamental la corporeidad del dibujo como marca autorial (Chute \& Dekoven, 2006; El Refaie, 2012: 49). La identidad autobiográfica no es únicamente la reconstrucción de una vida, sino que el medio del cómic, como artefacto simbólico, permite un discurso a través del cual la identidad se hace visible: el lugar desde el que se elabora el discurso narrativo negocia en dicho proceso el contexto en el que se instaura (Chaney, 2011: 3; Gilmore, 1995) permitiendo un acceso a una experiencia vivida de la cultura y de la lengua.

En el contexto del aprendizaje de idiomas, la identidad ha sido reconocida como un elemento fundamental para comprender y explicar la manera de acceder a un idioma y su cultura por parte de los aprendientes. La manera de posicionarse frente al idioma aprendido determina la inversión en tiempo y motivación de una persona respecto al aprendizaje. Norton (2012: 4) define la identidad en este contexto como: «[T] he way a person understands his or her relationship to the world, how that relationship is constructed across time and space, and how the person understands possibilities for the future.» En referencia a una lengua, la percepción individual determina el modo de acceso y, en última instancia, el aprendizaje de una lengua (Küster, 2013). Se trata, por otra parte, de un proceso de autocomprensión continuo en contextos sociales variables, en los cuales la representación de la lengua y la discursividad de dicha construcción cumplen un papel decisivo. El aprendizaje de una lengua va más allá de una competencia comunicativa que se pretenda, por un lado, neutral frente a contextos cambiantes y, por otro lado, instrumentalizable respecto a los procesos comunicativos en los que se aplica. Se trata más bien, como lo ha definido Kramsch (2006), de una competencia simbólica. La propuesta didáctica explota la construcción autobiográfica de la narración visual a fin de movilizar las competencias textual y visual en relación con la construcción autobiográfica y la variación lingüística. La experiencia decisiva de la protagonista respecto a diferentes

\footnotetext{
${ }^{1}$ La unidad de ambos sistemas simbólicos es omnipresente en la sociedad actual, sobre todo a través de las páginas de Internet. Para un análisis de dichas funciones cfr. Kress and Leeuwen (2001).
} 
usos del español permite un anclaje sociocultural para el desarrollo de la conciencia de la identidad lingüística de los aprendientes respecto a un sistema de la lengua pluricéntrico.

Las tareas fueron desarrolladas para grupos a partir del nivel B1, aplicables sobre todo con alumnos de edad superior a los 15 años. Se trata de tareas que pueden adecuarse a otros niveles de acuerdo a la composición del grupo, la edad de los aprendientes y los recursos lingüísticos y metalingüísticos que posean los mismos. Las tareas que se centran en los aspectos visuales pueden adaptarse, asimismo, a grupos de nivel inferior.

\section{Virus tropical: la construcción visual}

Powerpaola es el seudónimo de Paola Gaviria, artista nacida en Quito de padres colombianos. La elección de su nome de plume la cuenta en una secuencia publicada en el blog Historietas Reales (Powerpaola, 2008). Narra allí que, estando en París, se sube a un metro poblado de gente diversa. La vemos llorar sentada al lado de una persona de origen africano que le pregunta su nombre, a lo que ella responde, «Paola». Él no logra comprender y pregunta nuevamente «Power?». Tras repeticiones infructuosas él escribe en el billete de metro «Power». En la viñeta se ve la mano del personaje corrigiendo debajo de la línea magnética «Paol». La secuencia se cierra con el personaje que sale sonriendo del metro. La puesta en escena de este acto de empoderamiento determina la posición desde la que se enuncia. Un hecho que se ve reforzado por las influencias que Powerpaola reconoce del mundo del cómic, a saber, Julie Doucet (My New York Diary), las narraciones autobiográficas de Aline Kominsky o, también, la experiencia traumática de Debbie Drechsler (Daddy's Girl) (Powerpaola, 2016). Virus tropical lo firma Powerpaola, una voz narradora que une los parámetros establecidos para el género autobiográfico por Lejeune (1994: 14), es decir, la unidad de autora, narradora y protagonista. El gesto de empoderamiento que expresa el seudónimo Powerpaola modifica, sin embargo, el lugar desde el que se narra la trama de la novela gráfica quebrando la neutralidad respecto a los tres parámetros. La novela gráfica presenta una historia narrada cronológicamente en retrospectiva desde la gestación hasta los primeros pasos en el mundo de la ilustración y la puerta a la emancipación (coming of age). ${ }^{2} \mathrm{Se}$ trata, como es característico del género, de una obra de carácter referencial. ${ }^{3}$

La obra se divide en trece capítulos dibujados en blanco y negro con un estilo simple, un grado de esquematización importante, pero detallado y con diversos símbolos icónicos que enriquecen la narración. Cada capítulo está precedido por una portada que resume icónicamente el contenido del mismo y lleva un título abstracto como «Virus tropical», «La familia», «La religión», «Las mujeres», etc. ${ }^{4}$ La primera tarea consiste en analizar de forma global alguna de las portadas de los capítulos desde un punto de vista icónico en

\footnotetext{
2 Davis (2013: 191) denomina este subgénero biografías de la niñez y resalta por un lado la mirada infantil que impone muchas veces el narrador y el fin de la narración que coincide con la emancipación.

${ }^{3}$ La obra de Powerpaola posee algunas características que podrían caracterizarse como autoficcionales; no llega, a mi entender, a formar parte de dicha categoría textual, sino que se encuentra más cercana a la autobiografía gráfico-visual. Cfr. para una discusión de la autoficción literaria y su definición Casas (2012).

${ }^{4} \mathrm{El}$ resto de los capítulos se denominan «El dinero», «Las despedidas», «Los amigos», «La dolescencia», «Cali», «La identidad», «El trabajo», «El amor» $\mathrm{y}$ «El adiós» (Powerpaola, 2013: 15, 27, 39, 47, 59, 73, 91).
} 
cuanto a la unidad o contraste que presentan los elementos verbales y visuales (imágenes 1 y 2$)^{5}$

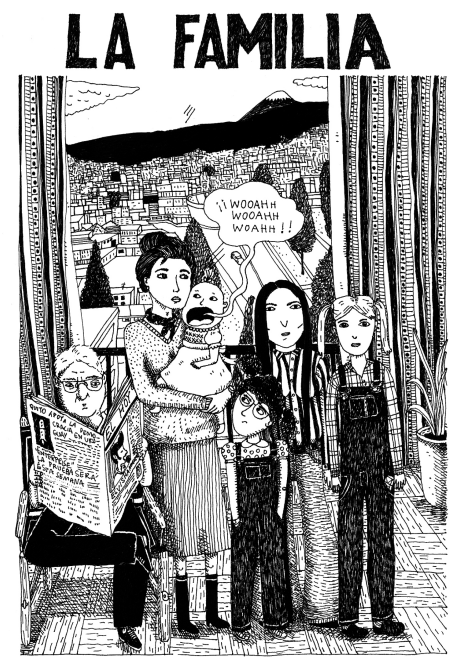

Imagen 1. La Editorial común (p. 15)
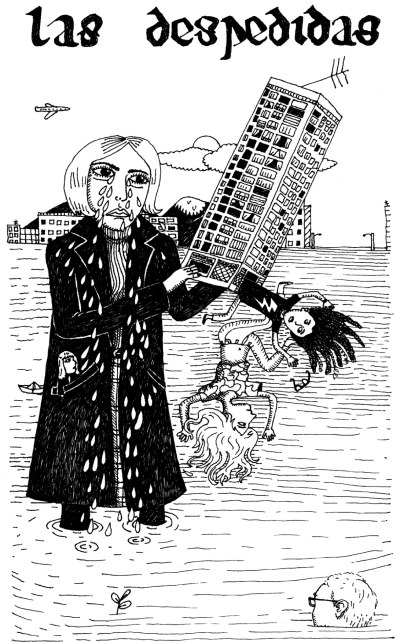

Imagen 2. La Editorial común (p. 59)

Se trata de identificar en primer lugar los signos visuales utilizados y reflexionar sobre su relación con el mensaje verbal. Como hay elementos que se repiten a lo largo de la novela gráfica, es recomendable que mediante esta introducción los aprendientes identifiquen símbolos (volcán, aviones, representación visual de los personajes a través de detalles que los identifican, etc.) a fin de poder analizar posteriormente sus funciones en la narración. En dichas portadas encontramos diversos elementos propios de la narración visual como el uso de onomatopeyas, líneas cinéticas o la esquematización y la hipérbole como elemento expresivo. Determinar los símbolos visuales y lingüísticos que construyen el mensaje resulta importante para ver de qué manera el código visual y verbal construyen una misma unidad significativa sin abandonar sus funciones expresivas independientes (Baetens \& Frey, 2015; Groensteen, 2007; Varillas, 2009). En las portadas, ambos códigos están coordinados, lo que permite identificar claramente elementos visuales que expresan el concepto abstracto denotado verbalmente y participan de manera coordinada con dicho mensaje. La coordinación y tensión entre ambos regímenes constituye uno de los recursos más importantes del cómic como medio.

El segundo paso consiste en formular hipótesis sobre las historias que se relatan en cada uno de los capítulos a través de los títulos y elementos visuales de las portadas, tarea que se puede desarrollar de forma oral y en grupos. El trabajo sobre la trama puede adaptarse de acuerdo al nivel y el material lingüístico tratado, pero puede variar desde la formulación de hipótesis sobre las posibles historias narradas en cada capítulo hasta una descripción más detallada de acciones y procesos de acciones que requiera conectores discursivos más complejos. A fin de mostrar el carácter de construcción de la identidad en la narración, los aprendientes elaborarán a continuación una lista de los títulos -que puede variar entre diez y trece - con los que cada uno dividiría su propia autobiografía. Se pueden mostrar todas las tapas de los capítulos de Virus tropical a modo de ejemplo

\footnotetext{
${ }^{5}$ La novela gráfica puede consultarse en la página web de Historietas reales en la siguiente dirección: https://historietasreales.wordpress.com/category/la-poderosa/
} 
y, a partir de ello, cada uno puede dibujar la portada de uno de los capítulos de la propia autobiografía con su correspondiente título.

El siguiente ejercicio ahonda en los aspectos narratológicos del cómic y se desarrolla en base a dos imágenes del primer capítulo de la novela gráfica (imágenes 3 y 4). Se trata primero de determinar quién habla en el primer capítulo del cómic, es decir, de diferenciar la función narrativa en las didascalias y las voces de los personajes en los globos de diálogo. Una de las estrategias para reconocer esta diferencia es atender al uso de los tiempos verbales (pretérito imperfecto e indefinido, presente) a fin de distinguir las voces. Como la narración autobiográfica se caracteriza por una voz narradora que habla retrospectivamente, pero el cómic como medio utiliza primariamente los globos de diálogo para establecer lo que dicen los personajes en un momento presente, el contraste entre las didascalias y los globos de diálogo resulta muy claro.

Posteriormente se establecen las relaciones tiempo-espacio en las páginas 8 y 9 (imágenes 3 y 4). En las mismas es posible reconocer los recursos del cómic para establecer un cronotopos. La división entre las viñetas, llamada gutter por su denominación en inglés, permite distinguir una escena de otra a nivel temporal y espacial de diversas maneras (McCloud, 1993: 74; Schüwer, 2008). En la imagen 3 la narración se centra en un solo escenario que ocupa ambas viñetas, separadas sin embargo por un espacio en blanco, pero el personaje de la madre se encuentra en dos posiciones diferentes del mismo, hecho que solo puede tener lugar en tiempos diferentes. Este uso poético de los recursos del medio permite desarrollar las competencias visuales de los alumnos. Se puede tematizar así el corte temporal y espacial que implica la división de la página en viñetas y la diferencia que permite establecer entre ambos planos.

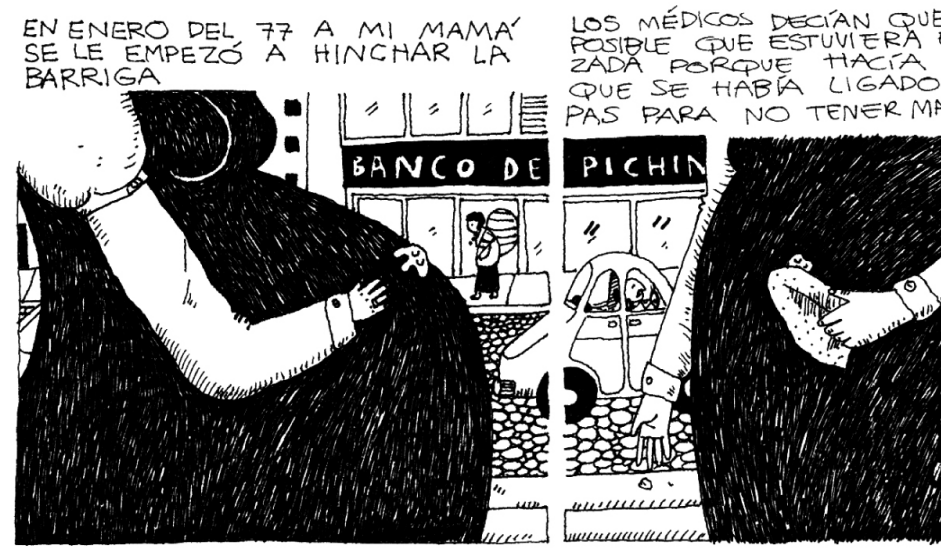

Imagen 3. La Editorial común (p. 8) 


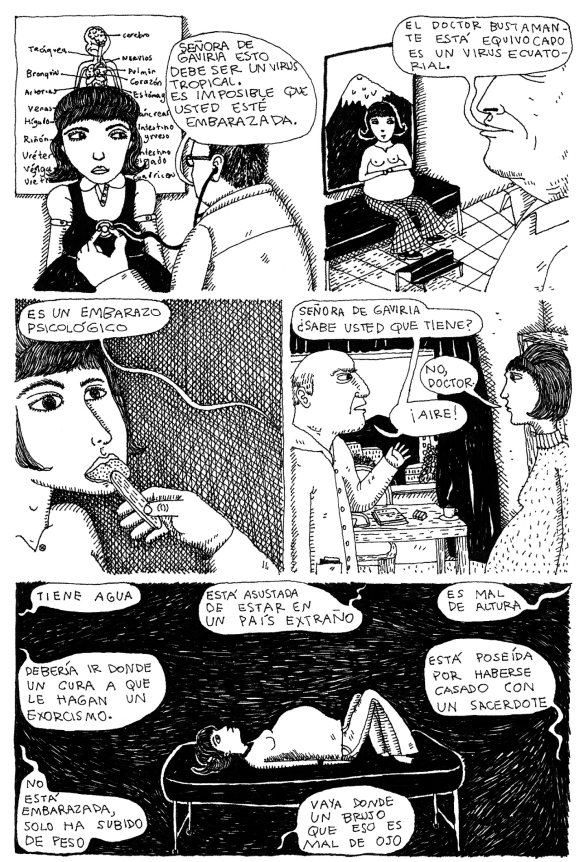

Imagen 4. La Editorial común (p. 9)

Mientras que en la imagen 3 se relatan hechos inmediatamente sucesivos en un mismo espacio, en la imagen 4 se representa una serie de escenas que requieren un tiempo más amplio entre una y otra. El foco del mensaje está aquí en la explicación del enigma en torno a la barriga hinchada de la madre, que no creía en un posible embarazo porque se había ligado las trompas para no tener más hijos. Las escenas recogen lo que fueron expresando los médicos para explicar la barriga hinchada. La última viñeta toma, a modo de clímax, el doble de espacio que el resto; encontramos al personaje de su madre acostada sola sobre un fondo negro con globos que recogen aseveraciones que solo pueden haber sido formuladas de manera sucesiva y por parte de diferentes actantes. La viñeta abre paso a una simultaneidad de tiempos diferentes y a una unidad de voces que enuncian desde diferentes espacios. Tras la discusión de estos elementos narratológicos los aprendientes formulan hipótesis sobre el desenlace del problema planteado en torno al personaje. Con ello se puede delimitar un elemento básico de toda narración, el planteo de un problema que necesita desarrollo y solución.

La comprensión textual implica reconocer la relevancia de las explicaciones que brindan los médicos acerca de la barriga hinchada (virus tropical, virus ecuatorial, embarazo psicológico, ¡Aire!, agua, susto por estar en un país extraño, mal de altura, poseída, sobrepeso, mal de ojo) y también los ámbitos sociales desde los que se enuncian. Paralelamente, la secuencia narrativa se analiza desde la perspectiva de la narradora, del personaje de la madre y del resto de los personajes (interrelación verbal-visual). La narradora manipula al lector presentando las afirmaciones verbales desde una voz extradiegética que parodia las explicaciones de los personajes: el recurso se puede mostrar a través de las primeras páginas de la novela gráfica (Powerpaola, 2013: 5-6), en las cuales vemos a los padres del futuro personaje teniendo relaciones sexuales y el recorrido de un espermatozoide hasta la fecundación de un óvulo. El lector de la novela gráfica 
sabe, por lo tanto, que las explicaciones que brindan los personajes resultan inverosímiles ante la situación planteada.

\section{Variación lingüística e identidad como competencia sociocultural}

Las siguientes tareas apuntan al desarrollo de las competencias socioculturales. Están centradas en el uso de las variedades del español en los diferentes espacios que construye la narración y de acuerdo a una variación de registros hablados. La tarea parte de la base de la variación lingüística que permite definir al español como una lengua pluricéntrica (Del Valle, 2014; López García, 2010; Moreno Fernández, 2010; Polzin-Haumann, 2012) y de la posibilidad de que los estudiantes desarrollen su identidad lingüística en relación con la conciencia de dichas variedades.

Si los aprendientes no tienen acceso a la obra, se puede hacer un resumen de la trama a fin de que comprendan más fácilmente las secuencias que se trabajarán a continuación. Una de las hermanas del personaje se muda de Quito (Ecuador) a Medellín (Colombia) y vuelve un año después hablando diferente (imagen 5), otra de las hermanas se muda posteriormente de Quito a Cali (Colombia) (imagen 6), pasos que seguirán la protagonista y la madre (imagen 7 ).

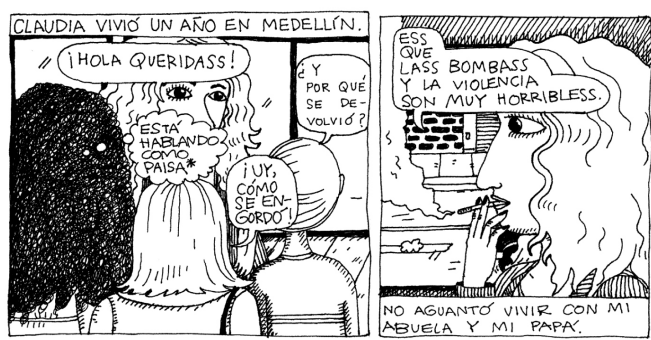

Imagen 5. La Editorial común (p. 66)

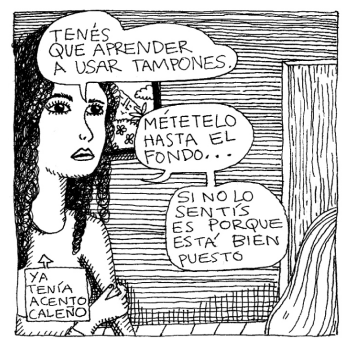

Imagen 6. La Editorial común (p.93)

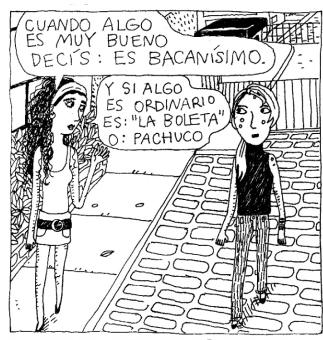

Imagen 7. La Editorial común (p. 101)

El primer ejercicio tiene como meta distinguir cómo se expresa visual y verbalmente el cambio en el uso de las variedades dialectales. Primero se formulan las preguntas siguientes: ¿Pertenecen al ámbito fonético, léxico, etc.? ¿Qué relevancia tiene para la protagonista el plurilingüismo interno o de variedades? En la imagen 5 se expresa a través de la articulación del fonema [s:], en la imagen 6 a través de la morfología verbal del voseo, y en la imagen 7, del uso léxico. Estas tres viñetas deben servir como anclaje para determinar la percepción de las variedades por parte de los aprendientes mediante otros ejemplos orales que pueden extraerse, por ejemplo, de La voces del español de la RAE (2011). Posteriormente los propios aprendientes describen situaciones en las que usos ajenos a la variedad aprendida les produjeron asombro o crearon dificultades, intentando describir qué elementos les resultaron llamativos respecto a su propia concepción normativa. Se discute a continuación si la percepción de las variedades va unida a una valoración de las mismas. El desarrollo de la conciencia, o su ausencia, respecto a la posición individual de los aprendientes frente a las variedades implica la capacidad de percibir diferencias y la conciencia de cómo se las valora. El docente solicita que marquen en un mapa las diferentes variedades del español que conocen y que nombren alguna característica de las mismas. Si no les es posible, deben buscar información de deberes y el docente tendrá que explicar brevemente qué es el pluricentrismo del español y resaltar 
las características del sistema de la lengua que se está enseñando en dicha aula. La meta es relacionar el plurilingüismo de variedades con el posicionamiento de los propios aprendientes frente a la lengua a fin de desarrollar la conciencia individual del concepto de español que cada uno posee implícitamente y que subyace a la enseñanza que están recibiendo. ${ }^{6}$

La siguiente tarea parte del relato de la experiencia que la propia protagonista realiza en un colegio de Cali tras haberse mudado desde Quito. El primer paso consiste en resumir oralmente el curso de acciones que recoge la secuencia de viñetas de las páginas 97 (imagen 8) y 98 a fin de establecer el problema al que se ve enfrentada la protagonista. En un paso siguiente se deben relacionar los elementos visuales con las expresiones de los alumnos: el docente puede guiar a los aprendientes en la distinción de aspectos diatópicos (voseo) y diafásicos (registro juvenil) para discutir con los alumnos qué aspectos del uso lingüístico se pueden distinguir como diatópicos y cuáles como diafásicos. El docente decidirá si es posible tratar estos aspectos a través de una nomenclatura científica o de manera informal acorde a las características del grupo.

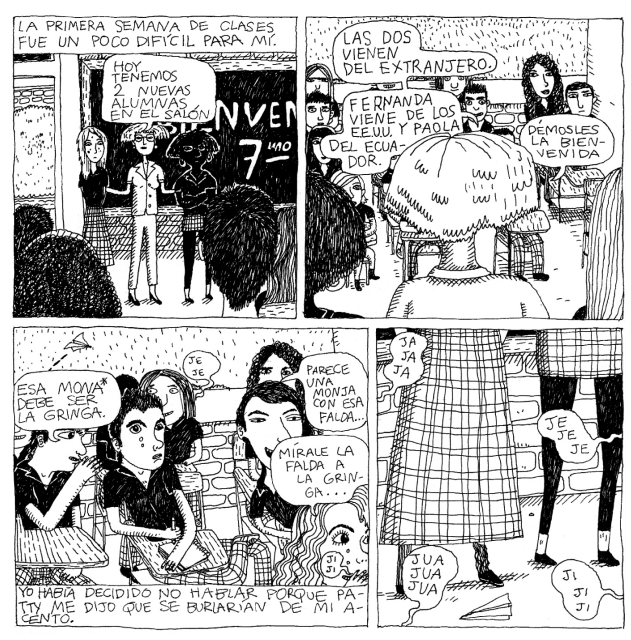

Imagen 8. La Editorial común (p. 97)

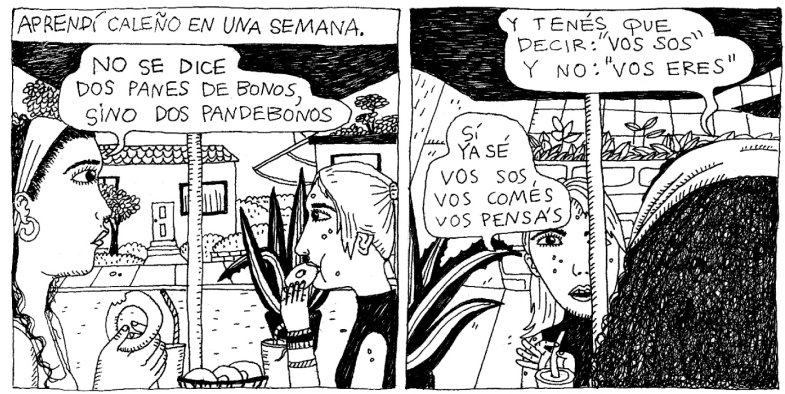

Imagen 9. La Editorial común (p. 101)

Esta secuencia se presta para tematizar experiencias personales graciosas o, por qué no, problemáticas en el uso del español u otra lengua extranjera que dominen los

\footnotetext{
${ }^{6} \mathrm{Si}$ los aprendientes no disponen del conocimiento geográfico correspondiente o desconocen las áreas geográficas en las que se habla español, puede introducirse la tarea como una forma de acercamiento a dichos lugares y culturas.
} 
aprendientes. La experiencia de la protagonista permite mostrar cómo el pasaje de un lugar a otro, aunque sea en un ámbito monolingüe, no está exento de dificultades también para un hablante nativo. Se discuten por ello a continuación los recursos que ponen en juego los propios aprendientes en una situación de este tipo y se comparan con la solución que encontró la propia protagonista (imagen 9). La última página de dicho capítulo (imagen 10) consta de una reconstrucción gráfica y verbal de las afrentas que recibió: la misma se presta para formular hipótesis sobre su significado, algunas más descriptivas, mientras que otras expresiones resultan más crípticas y dependientes del contexto. Todas están expresadas gráficamente de manera diferente, unas resaltan por su color negro sobre fondo blanco, otras por su tamaño, otras por el volumen de la letra, etc. Es posible incluir así las connotaciones y el valor afectivo que poseen las voces de una lengua para los individuos que la usan y las posibilidades de expresar dicha afectividad verbal y visualmente.

La tarea siguiente consiste en seleccionar una situación personal, positiva o negativa, y elaborar un póster análogo de voces que expresen gráficamente el sentimiento personal respecto a las mismas. Es posible aprovechar el plurilingüismo propio de los estudiantes para que expresen por medio del léxico y con la ayuda de una estrategia visual simple el posicionamiento y el componente emotivo frente a una situación determinada y crear la conciencia de los recursos que se poseen para expresarla, que pueden estar a disposición en español, en su propia lengua materna, o en otra que dominen.

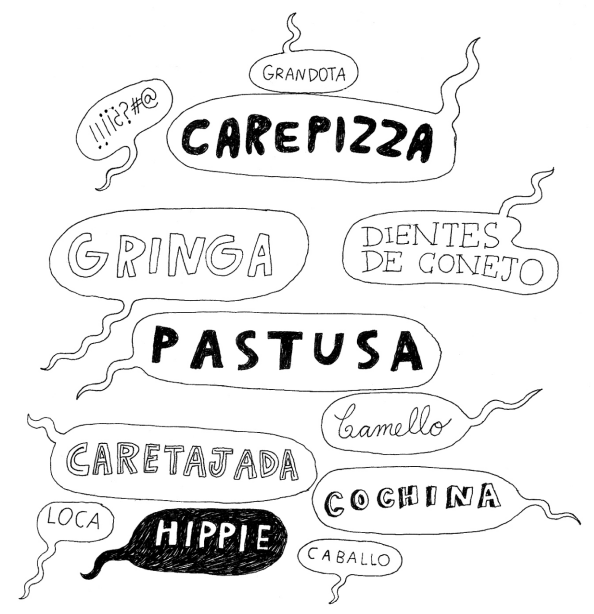

Imagen 10. La Editorial común (p. 102)

La experiencia de la protagonista permite acceder, por otra parte, a la identidad de los aprendientes respecto al español. Como hablantes diferentes, estos se posicionan de manera distinta frente a la lengua y sus ideales varían. No todos imaginan la comunidad de habla de la misma manera, no todos comparten los contextos en los que pretenden ser hablantes competentes (Kramsch, 1998: 65; Norton, 2012: 9). La imagen de los contextos, registros, el vocabulario que se pretende manejar es particular, por lo que la tarea final consistirá en elaborar una redacción en la que expresen los ideales que los propios aprendientes poseen como hablantes de español respecto a variedades, contextos, registros, vocabulario, etc. Por último se pueden comentar las diferentes posiciones identitarias y los ideales de los participantes en una puesta en común. 


\section{Conclusiones}

La secuencia didáctica permite de esta forma la identificación, conciencia y análisis de los recursos icónico-verbales del cómic desde una recepción de la configuración temporal-espacial del cómic y su relación con la narración autobiográfica. Se identifican las perspectivas -voces- discursivas y su uso en la configuración narrativa autobiográfica, que permite a través de una historia de vida desarrollar las competencias receptivas sobre el pluricentrismo del español en cuanto al uso de variedades, así como la integración de una diferenciación entre elementos diatópicos y diafásicos. Por último, el posicionamiento de los aprendientes frente a las variedades del español y la complejidad de dicho sistema de la lengua requiere de los aprendientes el desarrollo de la conciencia sobre su propia identidad y, de esta forma, el reconocimiento de cómo representan individualmente la comunidad de habla del español y dicho sistema de la lengua.

\section{Bibliografía}

ARNHEIM, R. (1986). El pensamiento visual. Barcelona: Paidós.

Baetens, J., \& Frey, H. (2015). The graphic novel. An introduction. New York: Cambridge Univ. Press.

CAsAs, A. (2012). «El simulacro del yo: la autoficción en la narrativa actual». En A. Casas (ed.), La autoficción. Reflexiones teóricas (pp. 9-42). Madrid: Arco Libros.

Chaney, M. H. (2011). Graphic Subjects. Critical Essays on Autobiography and Graphic Novels. Wisconsin: University of Wisconsin Press.

ChUte, H. L., \& Dekoven, M. (2006). «Introduction: Graphic Narrative». MFS Modern Fiction Studies, 52(4), 767-782.

DAVIS, R. G. (2013). «El cómic y las autobiografías de la niñez». En J. M. Trabado Cabado (ed.), La novela gráfica. Poéticas y modelos narrativos (pp. 287-313). Madrid: Arco Libros.

Del VAlle, J. (2014). «The Politics of Normativity and Globalization: Which Spanish in the Classroom?» The Modern Language Journal, 2014, Vol.98(1), pp.358-372.

El Refaie, E. (2012). Autobiographical Comics. Life Writing in Pictures. Jackson, Miss.: University Press of Mississippi.

Real Academia Española (2011). Las voces del español. Tiempo y espacio. Madrid: Espasa

GILmoRe, L. (1995). Autobiographics. A Feminist Theory of Women's Selfrepresentation. Ithaca, NY: Cornell University Press.

Groensteen, T. (2007). The System of Comics. Jackson, Miss.: University Press of Mississippi.

HeCKe, C., \& Surkamp, C. (2010). «Einleitung: Zur Theorie und Geschichte des Bildeneinsatzes im Fremdsprachenunterricht». En C. Hecke \& C. Surkamp (eds.), Bilder im Fremdsprachenunterricht (pp. 9-24). Tübingen: Gunter Narr. 
KRAMSCH, C. (1998). Language and culture. Oxford: Oxford University Press.

KramsCH, C. (2006). «From Communicative Competence to Symbolic Competence». Modern Language Journal, 90 (2), 249-252.

Kress, G. R., \& Leeuwen, T. v. (2001). Multimodal Discourse. The Modes and Media of Contemporary Communication. London: Arnold.

Kress, G. R., \& Leeuwen, T. v. (2006). Reading images. The grammar of visual design. London: Routledge.

KÜSTER, L. (2013). «Meine Sprachen - mein Leben. Sprachenlernen und Lerneridentitäten». En E. Burwitz-Melzer, F. G. Königs, \& C. Riemer (eds.), Identität und Fremdsprachenlernen. Anmerkungen zu einer komplexen Beziehung (pp. 143-152). Tübingen: Narr.

LeJeune, P. (1994). Der autobiographische Pakt. Frankfurt am Main: Suhrkamp.

LÓPez GARCíA, Á. (2010). Pluricentrismo, hibridación y porosidad en la lengua española. Madrid: Iberoamericana.

MCCloud, S. (1993). Understanding comics : the invisible art. Northampton, MA: Tundra Publications.

Mitchell, W. J. T. (1994). Iconology. Image, Text, Ideology. Chicago: University of Chicago Press.

Moreno Fernández, F. (2010). Las variedades de la lengua española y su enseñanza. Madrid: Arco Libros.

Norton, B. (2012). Identity and language Learning (2nd. ed.). Harlow: Longman.

Polzin-Haumann, C. (2012). «Standardsprache, Norm und Normierung». En J. Born, R. Folger, C. F. Laferl, \& B. Pöll (eds.), Handbuch Spanisch (pp. 44-54). Berlin: Erich Schmidt.

POWERPAOLA. (2008). ¿Que por qué me llamo Powerpaola? Recuperado el 28/08/2017, de https://historietasreales.wordpress.com/2008/07/04/que-por-que-me-llamopowerpaola-1-powerpaola/

PowerpaOla. (2013). Virus tropical. Barcelona: Random House Mondadori.

Powerpaola. (2016) Powerpaola: "Me inventé a una Paola mucho más valiente". Entrevista de J. Quintana. Revista Almagro. Recuperado el 28/08/2017, de http://almagrorevista.com.ar/powerpaola-me-invente-una-paola-mucho-mas-valiente/

Rose, G. (2001). Visual Methodologies. An Introduction to the Interpretation of Visual Materials (3rd. ed.). London: Sage.

SCHÜWER, M. (2008). Wie Comics erzählen. Grundriss einer intermedialen Erzähltheorie der grafischen Literatur. Trier: WVT.

VARILlas, R. (2009). La arquitectura de las viñetas. Texto y discurso en el cómic. Sevilla: Viaje a Bizancio. 